\title{
Relationship Between Prostate Volume and Lower Urinary Tract Symptom in Health Checkup Subjects
}

\author{
Hyeon Ju Kim ${ }^{1,2}$, Ji Hyun Moon ${ }^{1,2}$, Yun Hwan $\mathrm{Oh}^{1,2}$, Mi Hee Kong ${ }^{1,2}$, \\ Kyung Kgi Park ${ }^{3,4}$, Jung Sik Huh ${ }^{3,4}$ \\ ${ }^{1}$ Department of Family Medicine, Jeju National University Hospital, Jeju, Korea \\ ${ }^{2}$ Department of Family Medicine, School of Medicine, Jeju National University, Jeju, Korea \\ ${ }^{3}$ Department of Urology, Jeju National University Hospital, Jeju, Korea \\ ${ }^{4}$ Department of Urology, School of Medicine, Jeju National University, Jeju, Korea
}

\begin{abstract}
Purpose: This study aimed to evaluate the relationship between prostate volume and lower urinary symptom (LUTS) in subjects undergoing health checkup and to know the usefulness of TRUS in health screening. Materials and Methods: The study was conducted in 883 men aged $\geq 20$ years who underwent TRUS for health screening. All participants had filled in the international prostate symptom score (IPSS) and were tested for prostate-specific antigen; prostate volume, central gland volume, and transitional zone index were measured using TRUS. We analyzed the differences in the IPSS by prostate volume and differences in prostate volume by severity of LUTS and correlation between prostate volume and each component of IPSS.

Results: There were differences in the total IPSS, storage score, and voiding score between the subjects with prostate volumes of $\geq 30 \mathrm{~mL}$ or not ( $p=0.027, p=0.037$, and $p=0.029$, respectively). However, the differences were found only for urgency and weak stream. The volume of the severe symptom group was bigger than those of the mild and moderate symptom groups $(\mathrm{p}=0.002$ and $\mathrm{p}=0.014)$. The correlation between prostate volume and IPSS was significant only for the between the central volume and nocturia $(r=0.112, p<0.01)$.

Conclusions: The relationship between prostate volume and urinary symptoms showed significant but low correlation and found only in some components. For the accurate diagnosis, it would be more useful to accompany various voiding-related surveys in addition to TRUS during health screening. (Korean J Urol Oncol 2020;18:53-60)
\end{abstract}

Key Words: Prostate hyperplasia $\cdot$ Lower urinary tract symptoms $\cdot$ Ultrasonography $\cdot$ Diagnostic screening programs

\section{INTRODUCTION}

As economic improvement and advances in medical tech-

Received January 30, 2020, Revised March 11, 2020,

Accepted March 18, 2020

Corresponding Author: Jung Sik Huh

Department of Urology, Jeju National University, Aran 13gil 15,

Jeju 63241, Korea

E-mail: urohjs@jejunu.ac.kr

Tel: +82-64-754-8152, Fax: +82-64-757-8276

ORCID: https://orcid.org/0000-0003-2767-4390

- The research was supported by the Korean Society for Urologic Ultrasonograph Grant 2016. nology have lengthened the human lifespan, there are growing interests in increasing the quality of life. ${ }^{1}$ As a result of an increased lifespan, people may also experience diseases that had not been previously detected. With the growing awareness of the need for health screening for prevention and early detection of diseases, many hospitals are offering various personal health checkup programs in addition to national health screenings. Traditionally, health screening aims to lower the burden and mortality of a particular disease among individuals who do not have relevant symptoms.

With an increase in the elderly population, the incidence 2020 (C) Copyright The Korean Urological Oncology Society and The Korean Prostate Society. All Rights Reserved. 
of prostate diseases also rises, which consequently increases the demands for prostate diseases screening.

Prostatic enlargement resulting in benign prostatic hyperplasia (BPH) is a chronic, progressive disease which is common in male population mostly after the sixth decade. ${ }^{2}$ Lower urinary tract symptoms (LUTS) are also common conditions in middle-age or older men. ${ }^{3}$ LUTS are not only influenced by the size of the prostate but also by age, body weight, hormone changes, lifestyle, and chronic diseases, such as diabetes and stroke. The International Prostate Symptom Score (IPSS) is a useful and validated questionnaire to evaluate LUTS. ${ }^{4}$ Transrectal ultrasonography (TRUS) is often used as a diagnostic means for patients who present urinary symptoms and to facilitate prostate biopsy. When TRUS was performed for screening, it is often the patients' symptoms are not assessed and only the total prostate volume is measured. Some study showed the reliability of prostate volume measurement by TRUS seems to be questionable for the determination of the severity of LUTS. ${ }^{5}$ There are concerns about the accuracy and usefulness of TRUS in screening to evaluate the prostate disease. Thus, in this study, we measured the central gland volume as well as the total prostate volume using TRUS performed for health screening and also surveyed the IPSS. This study aimed to evaluate the relationship between prostate volume and lower urinary symptom (LUTS) in subjects undergoing health checkup and to know the usefulness of TRUS in health screening.

\section{MATERIALS AND METHODS}

Among men aged $\geq 20$ years who underwent TRUS for health screening at a health promotion center in Jeju between May 2015 and August 2017, those who completed the IPSS survey were enrolled in this study. Patients with prostate cancer, bladder cancer, cerebral infarction and history of prostate surgery or transurethral surgery and those who were taking male sex hormones and BPH medication were excluded.

All participants completed a self-reported questionnaire regarding their medical histories, highest educational attainment, income, marital status, smoking history, drinking history, and exercise history. The participants who drink at least 7 standard alcohol drinks at one time more than twice a week were classified into the high-risk alcohol user and those who exercise at least 3 times a week into the regular exercise group. The prostate volume was measured by 1 radiologist using TRUS, including total prostate volume, central gland volume and ratio of central gland volume to total prostate volume. The prostate volume was automatically measured using the following ellipsoid volume equation: height $(\mathrm{cm}) \times$ width $(\mathrm{cm}) \times$ length $(\mathrm{cm}) \times 0.523$. The main lesions detected on TRUS and prevalence of BPH were investigated in each age group, and the prevalence of BPH was subclassified by prostate volumes of $\geq 25 \mathrm{~mL}$ and $\geq 30 \mathrm{~mL}$. Furthermore, the differences in the IPSS by prostate volume and differences in the prostate volume by LUTS were analyzed. The correlation between the prostate volume and IPSS was analyzed by dividing the IPSS into the storage score and voiding score; the correlation was also analyzed for each item of IPSS. Statistical analyses were performed using the IBM SPSS Statistics ver. 20.0 (IBM Co., Armonk, NY, USA), and p-value of $<0.05$ was considered statistically significant.

The present study protocol was reviewed and approved by the Institutional Review Board (IRB) of Jeju National University Hospital (Reg. No. 2016-0803) and ensured that individuals were not identifiable by providing linkable anonymous data to the researchers. Waiver of informed consent for this study was approved by the IRB.

\section{RESULTS}

\section{Participants' General Characteristics}

A total of 883 participants were studied, and their mean age was $52.22 \pm 9.50$ years $(20-87$ years). The mean prostate-specific antigen level was $1.06 \pm 1.11 \mathrm{ng} / \mathrm{dL}(0.13-20.78$ $\mathrm{ng} / \mathrm{dL}$ ), and the mean prostate volume was $26.03 \pm 7.58 \mathrm{~mL}$ $(11.30-87.70 \mathrm{~mL})$. The total IPSS was $7.03 \pm 6.48(0-35)$. The mean storage score, including frequency, urgency, and nocturia, was $2.74 \pm 2.55(0-15)$, and the mean voiding score, including incomplete emptying, intermittency, weak stream, and straining, was $4.29 \pm 4.57$ points ( $0-20$ points). With regard to the prostate volume, 196 participants $(22.2 \%)$ had a volume of $<20 \mathrm{~mL} ; 464(52.5 \%), 20-30 \mathrm{~mL} ; 179$ (20.3\%), 30-40 mL; 34 (3.9\%), 40-50 mL; and 10 (1.1\%), $\geq 50 \mathrm{~mL}$; these findings showed that a volume of $20-30$ $\mathrm{mL}$ was the most common. A total of 335 participants 
(40.7\%) were smokers, and 327 (39.2\%) were classified into the high-risk drinking group and 228 participants (27.9\%) exercised regularly. Fourteen individuals $(2.5 \%)$ were single, and $507(91.8 \%)$ were married. Five hundred eighteen $(62.5 \%)$ were college graduates or higher, and $545(65.9 \%)$ had a monthly income of $\geq 4$ million Korean won, showing that many of the participants were highly educated and high income-earners. Prevalence of hypertension and diabetes mellitus was $25.4 \%$ and $12.4 \%$ respectively (Table 1 ).

\section{Prevalence of BPH and TRUS Findings}

The prevalence of BPH was $47.9 \%$ for the volume of $\geq 25$ $\mathrm{mL}$ and $25.3 \%$ for the volume of $\geq 30 \mathrm{~mL}$. The prostate volume increased with age. When BPH was defined as a prostate volume of $\geq 25 \mathrm{~mL}$, the prevalence of the BPH in the $20-39 \mathrm{~s}, 40 \mathrm{~s}, 50 \mathrm{~s}, 60 \mathrm{~s}$, and $\geq 70 \mathrm{~s}$ groups was $20.6 \%$, $34.0 \%, 52.8 \%, 72.9 \%$, and $72.5 \%$, respectively. When it was defined as a volume of $\geq 30 \mathrm{~mL}$, the prevalence was $8.8 \%, 13.1 \%, 28.0 \%, 45.3 \%$, and $50 \%$, respectively, showing that the prevalence of $\mathrm{BPH}$ increased with age ( $p$ $<0.001$ ) (Fig. 1).

The most common TRUS finding with the exception of the prostate volume was prostate calcification (54.1\%), with the prevalence of $33.8 \%, 49.2 \%, 57.5 \%, 61.2 \%$, and $72.5 \%$ in the $20-39 \mathrm{~s}, 40 \mathrm{~s}, 50 \mathrm{~s}, 60 \mathrm{~s}$, and $\geq 70 \mathrm{~s}$ groups, respectively, showing an increase in the prevalence with age $(\mathrm{p}<0.001)$. In addition, the second most common finding was cysts, followed by nodules and heterogeneous echoes $(8.6 \%, 2.8 \%$, and $2.3 \%$, respectively). Their prevalence also increased with age $(\mathrm{p}<0.001)$ (Fig. 2).

\section{Relationship Between the IPSS and Prostate Volume}

When the cutoff of the prostate volume was set to $25 \mathrm{~mL}$, there was difference only for nocturia $(p=0.017)$. When the cutoff was set to $30 \mathrm{~mL}$, the total IPSS $(\mathrm{p}=0.027)$, storage score, and voiding score significantly differed $(\mathrm{p}=0.037$ and $\mathrm{p}=0.029)$. However, when analyzed according to each symptom, there were significant differences only for urgency and weak stream $(\mathrm{p}=0.049$ and $\mathrm{p}=0.031$ ) (Table 2).

By comparison of the prostate volume after dividing into 3 groups according to LUTS, the volume of the severe symptom group was significantly bigger than those of the mild and moderate symptom groups $(p=0.02$ and $p=0.014)$;
Table 1. General characteristics of the study participants

\begin{tabular}{|c|c|}
\hline Characteristic & Value \\
\hline Age (yr) & $52.22 \pm 9.50(20-87)$ \\
\hline Height $(\mathrm{cm})$ & $169.49 \pm 5.88(153.0-189.3)$ \\
\hline Weight $(\mathrm{kg})$ & $75.75 \pm 11.24(49.4-130.2)$ \\
\hline Prostate volume $(\mathrm{mL})$ & $26.03 \pm 7.58(11.30-87.70)$ \\
\hline Prostate-specific antigen (ng/dL) & $1.06 \pm 1.11(0.125-20.779)$ \\
\hline Total testosterone & $5.52 \pm 1.86(0.22-13.14)$ \\
\hline Free testosterone & $12.05 \pm 4.26(2.11-42.57)$ \\
\hline \multicolumn{2}{|l|}{ IPSS } \\
\hline Total & $7.03 \pm 6.48(0-35)$ \\
\hline Storage score & $2.74 \pm 2.55(0-15)$ \\
\hline Frequency & $1.20 \pm 1.25(0-5)$ \\
\hline Urgency & $0.62 \pm 1.12\left(0^{-} 5\right)$ \\
\hline Nocturia & $0.91 \pm 0.89(0-5)$ \\
\hline Voiding score & $4.29 \pm 4.57(0-20)$ \\
\hline Incomplete emptying & $1.09 \pm 1.30(0-5)$ \\
\hline Intermittency & $0.96 \pm 1.36\left(0^{-} 5\right)$ \\
\hline Weak stream & $1.51 \pm 1.69(0-5)$ \\
\hline Straining & $0.73 \pm 1.20(0-5)$ \\
\hline \multicolumn{2}{|l|}{ Prostate volume $(\mathrm{mL})$} \\
\hline$\leq 20$ & $196(22.2)$ \\
\hline $20-30$ & $464(52.5)$ \\
\hline $30-40$ & $179(20.3)$ \\
\hline $40-50$ & $34(3.9)$ \\
\hline$>50$ & $10(1.1)$ \\
\hline Hypertension & $213(25.4)$ \\
\hline Diabetes & $104(12.4)$ \\
\hline Current smoker & $335(40.7)$ \\
\hline Alcohol use, high risk & $327(39.2)$ \\
\hline Regular exercise & $228(27.9)$ \\
\hline \multicolumn{2}{|l|}{ Marital status } \\
\hline Single & $14(2.5)$ \\
\hline Divorced/separated/widowed & $31(5.6)$ \\
\hline Marriage & $507(91.8)$ \\
\hline \multicolumn{2}{|l|}{ Education } \\
\hline Lower than middle & $73(8.8)$ \\
\hline High & $238(28.7)$ \\
\hline College or higher & $518(62.5)$ \\
\hline \multicolumn{2}{|l|}{ Monthly income $(10,000 \mathrm{KRW})$} \\
\hline$<200$ & $77(9.3)$ \\
\hline $200-400$ & $205(24.8)$ \\
\hline$>400$ & $545(65.9)$ \\
\hline
\end{tabular}

Values are presented as mean \pm standard deviation (range) or number $(\%)$.

High-risk alcohol users were defined as those consuming more than 7 standard alcoholic drinks at one time for more than twice a week. Regular exercise was defined as exercise for more than 3 times in a week.

IPSS: International Prostate Symptom Score, KRW: Korean won. 


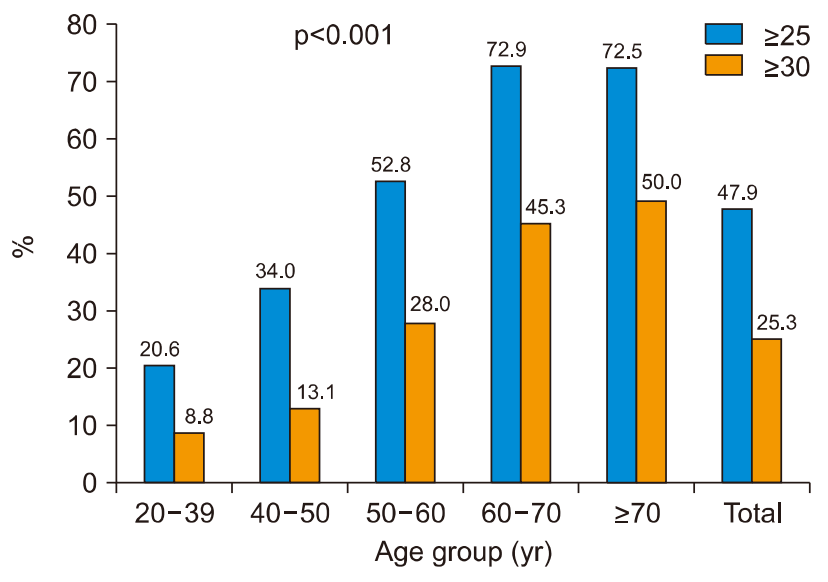

Fig. 1. Prevalence of benign prostatic hyperplasia according to age. The p-values were obtained using the chi-square test among the age groups.

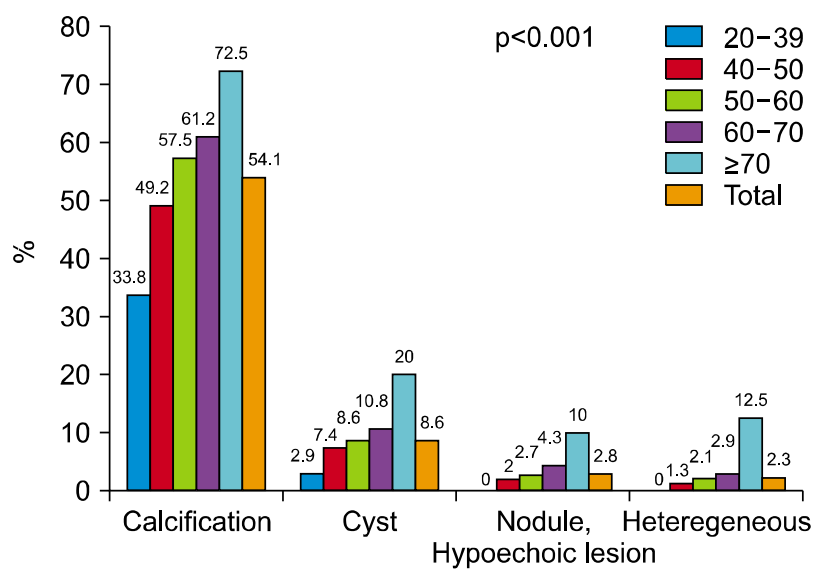

Fig. 2. Prevalence of prostate lesions on transrectal ultrasonography. The p-values were obtained using the chi-square test among the age groups.

Table 2. IPSS according to prostate volume

\begin{tabular}{|c|c|c|c|c|c|c|}
\hline \multirow[b]{2}{*}{ IPSS } & \multicolumn{2}{|c|}{ Prostate volume } & \multirow[b]{2}{*}{ p-value } & \multicolumn{2}{|c|}{ Prostate volume } & \multirow[b]{2}{*}{ p-value } \\
\hline & $\begin{array}{l}<25 \mathrm{~mL} \\
(\mathrm{n}=460)\end{array}$ & $\begin{array}{l}\geq 25 \mathrm{~mL} \\
(\mathrm{n}=423)\end{array}$ & & $\begin{array}{l}<30 \mathrm{~mL} \\
(\mathrm{n}=660)\end{array}$ & $\begin{array}{l}\geq 30 \mathrm{~mL} \\
(\mathrm{n}=223)\end{array}$ & \\
\hline Total & $6.74 \pm 6.42$ & $7.35 \pm 6.54$ & 0.161 & $6.73 \pm 6.28$ & $7.91 \pm 6.70$ & 0.027 \\
\hline Storage score & $2.61 \pm 2.48$ & $2.87 \pm 2.61$ & 0.127 & $2.63 \pm 2.42$ & $3.04 \pm 2.87$ & 0.037 \\
\hline Frequency & $1.19 \pm 1.22$ & $1.22 \pm 1.29$ & 0.756 & $1.17 \pm 1.21$ & $1.30 \pm 1.37$ & 0.191 \\
\hline Urgency & $0.58 \pm 1.08$ & $0.67 \pm 1.16$ & 0.216 & $0.58 \pm 1.07$ & $0.75 \pm 1.24$ & 0.049 \\
\hline Nocturia & $0.85 \pm 0.89$ & $0.99 \pm 0.89$ & 0.017 & $0.89 \pm 0.88$ & $1.00 \pm 0.93$ & 0.128 \\
\hline Voiding score & $4.12 \pm 4.50$ & $4.48 \pm 4.63$ & 0.248 & $4.10 \pm 4.46$ & $4.87 \pm 4.83$ & 0.029 \\
\hline Incomplete emptying & $1.08 \pm 1.30$ & $1.11 \pm 1.31$ & 0.730 & $1.05 \pm 1.27$ & $1.20 \pm 1.41$ & 0.180 \\
\hline Intermittency & $0.92 \pm 1.35$ & $1.00 \pm 1.37$ & 0.339 & $0.91 \pm 1.31$ & $1.10 \pm 1.48$ & 0.076 \\
\hline Weak stream & $1.45 \pm 1.69$ & $1.57 \pm 1.69$ & 0.283 & $1.44 \pm 1.67$ & $1.72 \pm 1.73$ & 0.031 \\
\hline Straining & $0.68 \pm 1.16$ & $0.79 \pm 1.26$ & 0.171 & $0.69 \pm 1.16$ & $0.85 \pm 1.31$ & 0.097 \\
\hline
\end{tabular}

Values are presented as mean \pm standard deviation.

The p-values were obtained using the independent t-test.

IPSS: International Prostate Symptom Score.

however, there was no difference of the prostate volumes between the mild and moderate symptom groups $(p=0.727)$. Similarly, the central gland volume of the severe symptom group was significantly bigger than those of the mild and moderate symptom groups $(\mathrm{p}=0.012$ and $\mathrm{p}=0.020)$; however, there was no difference of the prostate volumes between the mild and moderate symptom groups $(p=0.298)$. The transitional zone index (TZI) was not associated with the severity of the prostate symptoms $(p=0.102)$ (Table 3$)$.

As correlation coefficients ( $r$ ) is meaningful at least over than 0.1 or less than -0.1 and $p$-value of $<0.05$ was considered statistically significant, there was significant correlation only for the between the central volume and nocturia when analyzing the correlations between prostate volume and each component of IPSS $(r=0.112, p<0.001)$ (Table 4). In addition, there was no meaningful correlation between prostate-specific antigen value and each component of IPSS.

\section{DISCUSSION}

The prostate tends to increase in volume with age, and symptoms, such as urinary frequency, nocturia, weak stream, and intermittency occur because of the elevated concentration of prostatic stromal or epithelial cells. LUTS are 
Table 3. Difference between the prostate volume according to severity of prostate symptoms

\begin{tabular}{|c|c|c|c|c|c|c|c|}
\hline Variable & $\begin{array}{l}\text { Mild }(0-7) \\
\quad(\mathrm{n}=580)\end{array}$ & $\begin{array}{c}\text { Moderate }(8-19) \\
\quad(n=247)\end{array}$ & $\begin{array}{c}\text { Severe }(20-35) \\
\quad(\mathrm{n}=56)\end{array}$ & $\mathrm{p}$-value & p-value ${ }^{a)}$ & p-value ${ }^{\text {b) }}$ & p-value ${ }^{c)}$ \\
\hline Total prostate volume & $25.68 \pm 7.54$ & $26.12 \pm 6.97$ & $29.26 \pm 9.70$ & 0.003 & 0.727 & 0.002 & 0.014 \\
\hline Central gland volume & $9.29 \pm 3.48$ & $9.70 \pm 3.37$ & $11.16 \pm 5.45$ & 0.001 & 0.298 & 0.012 & 0.020 \\
\hline TZI & $0.36 \pm 0.07$ & $0.37 \pm 0.07$ & $0.38 \pm 0.08$ & 0.102 & 0.199 & 0.275 & 0.837 \\
\hline
\end{tabular}

Values are presented as mean \pm standard deviation.

The p-values were obtained using analysis of variance.

${ }^{a)}$ p-value: mild vs. moderate; ${ }^{b)}$ p-value: mild vs. severe; ${ }^{c)}$ p-value: moderate vs. severe using the post hoc test.

TZI: transitional zone index.

Table 4. Correlation between the prostate volume and IPSS

\begin{tabular}{cccccccccccc}
\hline Variable & & Total IPSS & $\begin{array}{c}\text { Incomplete } \\
\text { Emptying }\end{array}$ & Frequency & $\begin{array}{c}\text { Intermitt } \\
\text { ency }\end{array}$ & Urgency & $\begin{array}{c}\text { Weak } \\
\text { stream }\end{array}$ & Straining Nocturia & $\begin{array}{c}\text { Storage } \\
\text { score }\end{array}$ & $\begin{array}{c}\text { Voiding } \\
\text { score }\end{array}$ \\
\hline Total prostate & $\mathrm{r}$ & 0.080 & 0.039 & 0.027 & 0.059 & 0.057 & 0.076 & 0.072 & 0.086 & 0.068 & 0.076 \\
volume & $\mathrm{p}$-value & 0.017 & 0.248 & 0.422 & 0.082 & 0.092 & 0.024 & 0.032 & 0.011 & 0.043 & 0.024 \\
Central gland & $\mathrm{r}$ & 0.099 & 0.038 & 0.066 & 0.069 & 0.064 & 0.084 & 0.086 & 0.112 & 0.099 & 0.085 \\
volume & $\mathrm{p}$-value & 0.003 & 0.264 & 0.051 & 0.040 & 0.059 & 0.012 & 0.011 & 0.001 & 0.003 & 0.012 \\
TZI & $\mathrm{r}$ & 0.058 & 0.020 & 0.065 & 0.034 & 0.037 & 0.038 & 0.033 & 0.086 & 0.078 & 0.037 \\
& $\mathrm{p}$-value & 0.085 & 0.550 & 0.053 & 0.317 & 0.227 & 0.254 & 0.321 & 0.010 & 0.020 & 0.269 \\
\hline
\end{tabular}

The correlation coefficients (r) and p-values were calculated using Pearson correlation model.

IPSS: International Prostate Symptom Score, TZI: transitional zone index.

caused by various factors, one of which is BPH. The definition of BPH varies by study; it is sometimes defined as a prostate volume of $\geq 25 \mathrm{~mL}$ or $\geq 30 \mathrm{~mL}$ on TRUS. ${ }^{4}$ The prevalence of $\mathrm{BPH}$ tends to increase with age. In a cross-sectional study on adults living in the Jeju island, the prevalence was approximately $21 \%$; the rates were $11.6 \%$, $18.1 \%, 30.8 \%$, and $50.8 \%$ in patients in their $50 \mathrm{~s}, 60 \mathrm{~s}, 70 \mathrm{~s}$, and $80 \mathrm{~s}$, respectively. ${ }^{6}$ In this study, the prevalence of BPH also tended to rise with age; particularly, the prevalence was $47.9 \%$ when BPH was defined as a volume of $\geq 25 \mathrm{~mL}$ and $25.3 \%$ when defined as a volume of $\geq 30 \mathrm{~mL}$. The prevalence of BPH for prostate volumes of $\geq 25 \mathrm{~mL}$ and $\geq 30 \mathrm{~mL}$ in the $60 \mathrm{~s}$ group was $72.9 \%$ and $45.3 \%$, respectively; that in the 70 s group was $72.5 \%$ and $50.0 \%$, respectively, showing a prevalence higher than those reported in previous studies. This is speculated to reflect the high demands for prostate screening of individuals with urinary symptoms. The causes of BPH include aging and male sex hormones, and it is also associated with race, obesity, hypertension, and smoking. ${ }^{7-9}$ The previous our study also found that the prostate volume is significantly correlated with body mass index (BMI), waist circumference, and vis- ceral fat area. ${ }^{10}$ In a retrospective cohort study in Korea, abdominal obesity is positively associated with prostate enlargement. ${ }^{11}$ But in other study, LUTS was not significantly associated with BMI, waist circumference, blood pressure and glucose level ${ }^{12}$ and our study showed similar results. LUTS could be caused by various factors not only prostate volume.

The prevalence of LUTS is generally above $50 \%$, but ranges widely from $23 \%$ to $83 \%$ in South Korea. ${ }^{13-16}$ In a study on Chinese, Taiwanese, and Korean adults, more than $60 \%$ of the total population had such symptoms; the prevalence was higher among men than among women and increased with age. ${ }^{17}$ In a study on adults aged $\geq 40$ years, the prevalence of symptoms related to storage was $16.2 \%$ in men and $30.5 \%$ in women; that of nocturia, frequency, and weak stream was $36 \%, 30 \%$, and $29 \%$, respectively and LUTS prevalence was not affected by education level or marital status in the overall population and associated with marital status in only women. ${ }^{12}$ There were no associations between marital status, education, incomes with LUTS in our study. In our study, subjects who took antihypertensive medication or diabetes were slightly higher in severe LUTS 
group, but it was not statistically significant. In one study on patients with BPH and LUTS, men with hypertension are more likely to have a higher IPSS and large prostate volume than men without hypertension. ${ }^{18}$ But there was no significant difference of variables between subjects with diabetes mellitus, smoking or dyslipidemia and without cardiovascular risk factors.

In our study total IPSS, storage score, and voiding score significantly differed when the cutoff of the prostate volume was set to $30 \mathrm{~mL}$. However, when analyzed according to each symptom, there were significant differences only for urgency and weak stream. When the cutoff of the prostate volume for $\mathrm{BPH}$ was set to $25 \mathrm{~mL}$, there was difference only for nocturia. By comparison of the prostate volume after dividing into 3 groups according to LUTS, the volume of the severe symptom group differed from those of the mild and moderate symptom groups however, the prostate volumes between the mild and moderate symptom groups did not significantly. There was no difference of the TZI among groups divided by the severity of the prostate symptoms. The severity of LUTS can increase in relation to the prostate volume. But it showed only comparing with the severe symptom group. If LUTS was mild or moderate it is needed to assess the additional causes. With regard to the correlation between the prostate volume and IPSS, the central gland volume was correlated with nocturia, but not with other factors. Choi et al. ${ }^{19}$ reported that the association between the TZI and LUTS among whites, Hispanics, and Koreans, and Koreans showed a higher TZI and higher prevalence of LUTS. In this study, the TZI tended to increase with increasing severity of LUTS; however, the association was not significant. Hence, there may be other factors except increased transitional zone volume that affect voiding symptoms. Although the size of the prostate gland and urinary symptom are somewhat related, the only TRUS in health screening does not completely reflect the urinary symptom. Tatar et al. ${ }^{5}$ analyzed the value of prostate gland volume measurement by TRUS in prediction of severity of LUTS. The study showed low correlation between IPSS and prostate volume measurement by TRUS. So they insisted prostate volume measurement by TRUS is a poor predictor for the determination of the severity of LUTS therefore IPSS should be primarily considered for the determination of the severity of LUTS. Their results were similar with our study.

It is necessary to fully understand the symptoms of the patient through questionnaires on urinary symptom. Therefore, it should be able to resolve urinary symptom through accurate diagnosis by performing TRUS, uroflowmetry, questionnaires for urinary symptom, such as IPSS, overactive bladder (OAB) symptoms score, OAB questionnaire, and King's Health Questionnaire.

TRUS can be also used to diagnose calcifications, cysts, and nodules. The prevalence of prostate calcification varies widely from $13.8 \%$ to $100 \%$, and it is often discovered with $\mathrm{BPH}$ and prostate cancer. ${ }^{20-24}$ Large or diffuse calcifications within adenomata produce acoustic shadowing. Prostatic adenomata are arising more commonly in hypoechoic nodule and mixed echogenicity. ${ }^{25}$ Cystic lesions identified with TRUS include müllerian duct cyst, prostatic utricle cyst, ejaculatory duct cyst, cystic degeneration in $\mathrm{BPH}$, prostatic retention cyst, cavitary prostatitis, and prostatic abscess. ${ }^{26}$

In the study on patients visiting a health promotion center and urology outpatients, the prevalence of prostate calcification was $36.1 \%$ and $48.3 \%$, respectively, showing a higher prevalence among the latter. However, there were no differences in the size, location, and number, and the urology outpatients showed more frequent LUTS. $^{27}$

In this study, the prevalence of prostate calcification was $54.1 \%$, which increased with age; the prevalence increased to $61.2 \%$ in the $60 \mathrm{~s}$ group and $72.5 \%$ in the $\geq 70$ s group. The incidence of midline prostatic cyst ranges from $1 \%$ to $14 \%$ among patients with voiding symptoms. ${ }^{28-32}$ In one study, the incidence was approximately $28 \%$ among healthy adults, $29.5 \%$ among adults in their $40 \mathrm{~s}$, and $31.4 \%$ among adults in their $60 \mathrm{~s} .{ }^{33}$ In this study, the overall incidence of prostatic cysts was $8.6 \%$ and $10.8 \%$ in the 60 s group and $20.0 \%$ in the 70 s group, showing that it increases with age.

This study has some limitations. This study was conducted in a single health screening center; thus, the data cannot represent Korea's entire population. Although there were strengths as basic data and distribution by analyzing all age groups including asymptomatic people, it might affect the reliability of results that range of variables was wide and heterogeneous such as age (20-87 years) or prostate volume $(11-87 \mathrm{~mL})$. Further, the quality of life item was missed in the IPSS survey and did not perform digital rectal examination. Lastly, the uroflowmetry was not 
included. Complicated and invasive studies are not necessary for health screening, but survey about voiding symptoms is basically recommended in company with TRUS because prostate volume measurement by TRUS is a poor predictor for the determination of the severity of LUTS.

\section{CONCLUSIONS}

The relationship between prostate volume and urinary symptoms showed significant but low correlation and found only in some components. Thus, the TRUS alone in health screening does not completely reflect the urinary symptoms. It is necessary to fully understand the symptoms of the patient through questionnaires on urinary symptoms because LUTS may be caused by various factors. When the IPSS is high, additional tests should be performed to differentiate $\mathrm{BPH}$ from other urologic diseases that may cause LUTS. It would be more useful to accompany various voiding-related surveys in addition to TRUS during health screening.

\section{CONFLICT OF INTEREST}

The authors claim no conflicts of interest.

\section{REFERENCES}

1. Huh JS. The overview of hopice care of urologist. Korean J Urol Oncol 2017;15:16-20.

2. Emberton M, Andriole GL, de la Rosette J, Djavan B, Hoefner K, Vela Navarrete R, et al. Benign prostatic hyperplasia: a progressive disease of aging men. Urology 2003;61:267-73.

3. Cornu JN, Cussenot O, Haab F, Lukacs B. A widespread population study of actual medical management of lower urinary tract symptoms related to benign prostatic hyperplasia across Europe and beyond official clinical guidelines. Eur Urol 2010;58:450-6.

4. Barry MJ, Fowler FJ Jr, O'Leary MP, Bruskewitz RC, Holtgrewe HL, Mebust WK, et al. The American Urological Association symptom index for benign prostatic hyperplasia. The Measurement Committee of the American Urological Association. J Urol 1992;148:154957.

5. Tatar IG, Ergun O, Celtikci P, Birgi E, Hekimoglu B. Value of prostate gland volume measurement by transrectal US in prediction of the severity of lower urinary tract symptoms. Med Ultrason 2014;16:315-8.

6. Huh JS, Kim YJ, Kim SD. Prevalence of benign prostatic hyperplasia on Jeju island: analysis from a cross-sectional community-based survey. World J Mens Health 2012; 30:131-7.

7. Lee C, Kozlowski JM, Grayhack JT. Etiology of benign prostatic hyperplasia. Urol Clin North Am 1995;22: 237-46.

8. Dahle SE, Chokkalingam AP, Gao YT, Deng J, Stanczyk FZ, Hsing AW. Body size and serum levels of insulin and leptin in relation to the risk of benign prostatic hyperplasia. J Urol 2002;168:599-604.

9. Ziada A, Rosenblum M, Crawford ED. Benign prostatic hyperplasia: an overview. Urology 1999;53:1-6.

10. Park JS, Moon JH, Huh JS, Kong MH, Kim HJ. Comparison of correlation between prostate volume and obesity indices. Korean J Obs 2015;24:95-100.

11. Jung JH, Ahn SV, Song JM, Chang SJ, Kim KJ, Kwon $\mathrm{SW}$, et al. Obesity as a risk factor for prostatic enlargement: a retrospective cohort study in Korea. Int Neurourol J 2016;20:321-8.

12. Kim TH, Han DH, Lee KS. The prevalence of lower urinary tract symptoms in korean men aged 40 years or older: a population-based survey. Int Neurourol J 2014;18: 126-32.

13. Coyne KS, Sexton CC, Thompson CL, Milsom I, Irwin D, Kopp ZS, et al. The prevalence of lower urinary tract symptoms (LUTS) in the USA, the UK and Sweden: results from the Epidemiology of LUTS (EpiLUTS) study. BJU Int 2009;104:352-60.

14. Irwin DE, Milsom I, Hunskaar S, Reilly K, Kopp Z, Herschorn S, et al. Population-based survey of urinary incontinence, overactive bladder, and other lower urinary tract symptoms in five countries: results of the EPIC study. Eur Urol 2006;50:1306-14.

15. Choi H, Bae JH. Overview of the epidemiology of lower urinary tract dysfunction in South Korea. Int Neurourol J 2016;20:91-100.

16. Chapple C, Castro-Diaz D, Chuang YC, Lee KS, Liao L, Liu SP, et al. Prevalence of lower urinary tract symptoms in China, Taiwan, and South Korea: results from a cross-sectional, population-based study. Adv Ther 2017; 34:1953-65.

17. Yoo TK, Lee KS, Sumarsono B, Kim ST, Kim HJ, Lee $\mathrm{HC}$, et al. The prevalence of lower urinary tract symptoms in population aged 40 years or over, in South Korea. Investig Clin Urol 2018;59:166-76.

18. Hwang EC, Kim SO, Nam DH, Yu HS, Hwang I, Jung SI, et al. Men with hypertension are more likely to have severe lower urinary tract symptoms and large prostate volume. Low Urin Tract Symptoms 2015;7:32-6.

19. Choi J, Ikeguchi EF, Lee SW, Choi HY, Te AE, Kaplan 
SA. Is the higher prevalence of benign prostatic hyperplasia related to lower urinary tract symptoms in Korean men due to a high transition zone index? Eur Urol 2002; 42:7-11.

20. Park SW, Nam JK, Lee SD, Chung MK. Are prostatic calculi independent predictive factors of lower urinary tract symptoms? Asian J Androl 2010;12:221-6.

21. FOX M. The natural history and significance of stone formation in the prostate gland. J Urol 1963;89:716-27.

22. Søndergaard G, Vetner M, Christensen PO. Prostatic calculi. Acta Pathol Microbiol Immunol Scand A 1987; 95:141-5.

23. Horio Y. On the morphological alteration of the prostate gland in aging. I. A histopathologic study of the prostate gland and the testis in aging and the correlation of their senile changes. Nihon Hinyokika Gakkai Zasshi 1967;58: 783-813.

24. Geramoutsos I, Gyftopoulos K, Perimenis P, Thanou V, Liagka D, Siamblis D, et al. Clinical correlation of prostatic lithiasis with chronic pelvic pain syndromes in young adults. Eur Urol 2004;45:333-7.

25. Dunnick NR, Sandler CM, Newhouse JH, Amis ES. Textbook of uroradiology. 3rd ed. Philadelphia (PA): Lippincott Williams \& Wilkins; 2001;394-413.

26. Nghiem HT, Kellman GM, Sandberg SA, Craig BM. Cystic lesions of the prostate. Radiographics. 1990 Jul;10(4):635-50. Review. Erratum in: Radiographics
1990;10:963.

27. Hong CG, Yoon BI, Choe HS, Ha US, Sohn DW, Cho YH. The prevalence and characteristic differences in prostatic calcification between health promotion center and urology department outpatients. Korean J Urol 2012;53: 330-4.

28. Slocum RC. Muellerian duct cysts. Trans Southeast Sect Am Urol Assoc 1954;(18th Annual Meeting):26-34.

29. Higashi TS, Takizawa K, Suzuki S, Nagashima J, Tamura S, Obuchi M, et al. Müllerian duct cyst: ultrasonographic and computed tomographic spectrum. Urol Radiol 1990;12:39-44.

30. Dik P, Lock TM, Schrier BP, ZeijlemakerBY, Boon TA. Transurethral marsupialization of a medial prostatic cyst in patients with prostatitis-like symptoms. J Urol 1996;155: 1301-4.

31. Galosi AB, Montironi R, Fabiani A, Lacetera V, Gallé G, Muzzonigro G. Cystic lesions of the prostate gland: an ultrasound classification with pathological correlation. J Urol 2009;181:647-57.

32. Curran S, Akin O, Agildere AM, Zhang J, Hricak H, Rademaker J. Endorectal MRI of prostatic and periprostatic cystic lesions and their mimics. AJR Am J Roentgenol 2007;188:1373-9.

33. Lee EK, Kim SH, Lee YS. Midline cysts in the prostate: incidence in healthy men on transrectal ultrasonography (TRUS). J Korean Soc Ultrasound Med 2011;30:271-6. 